\title{
ANATOMICAL STUDY OF GERDY'S TUBERCLE, ITS SHAPE, TEXTURE AND CLINICAL APPLICATION.
}

\footnotetext{
1. MBBS, M.Phil

Assistant Professor Anatomy

Faisalabad Medical University

Faisalabad.

2. MBBS, M.Phil, MBA (HM)

Professor Anatomy

Independent Medical College

Faisalabad

3. MBBS

APMO Anatomy

Faisalabad Medical University Faisalabad.
}

\section{Correspondence Address:}

Dr. Anwaar Hussain

Department of Anatomy

Faisalabad Medical University

Faisalabad.

doctoranwaarh@yahoo.com

Article received on:

09/07/2019

Accepted for publication:

02/10/2019

\begin{abstract}
Anwaar Hussain 1 , Irfan Ahmed Mughal ${ }^{2}$, Muhammad Hanif ${ }^{3}$
ABSTRACT... Objectives: The objective of this study is to lay emphasis on Gerdy's tubercle, its morphology and clinical significance of Gerdy's safe area in upper lateral part of tibia for any surgical intervention to avoid injury to neighboring common peroneal nerve. Study Design: Comparative anatomical study. Setting: Anatomy Department Faisalabad Medical University Faisalabad. Period: From $1^{\text {st }}$ September 2018 to $20^{\text {th }}$ Feb 2019. Material \& Methods: Total 72 dried Pakistani tibia irrespective of sex (38 right and 34 left) were taken from the bone bank of Anatomy Department FMU. The upper end of tibia was studied with respect to the shape and texture of Gerdy's tubercle. The shape is divided in to Group A having triangular, Group B oval, Group $C$ irregular and group D unidentified in both right and left bones and their \% age was calculated. Similarly the texture Of GT was divided in to Group A facet (smooth), Group B tubercle (rough) and Group C unidentified in both right and left tibia and then \% age was calculated. Results: Total 72 dried human tibia were examined out of which 38 were of right side and rest 34 were of left side all showed presence of Gerdry's tubercle. Regarding shape of GT Right tibia showed 12(31.5\%) triangular (group A), Oval shape was 20 (52.6\%) (Group B), number of irregular was 6 (15.9\%) (Group C) and none unidentified (0\%) (Group D). Regarding texture GT Right Tibia showed facet type Group A 16(42\%), Group B 57\% were of tubercle type (22) and non unidentified (Group D) Zero \%. Total 34 left tibia Shape of GT was examined and found triangular (group A) in 18 tibia (52\%) and oval shaped 6(17.6\%) in group B. Whereas in group C 10 (29.4\%). were irregular. The texture of left tibia $41.1 \%$ (14) were of facet Type Group $\mathrm{A}$ and $58.82 \%$ (20) were of tubercle type (group B). Total Number of Tibia $(\mathrm{N}=72)$ GT showed $41.6 \%$ triangular, $36.1 \%$ oval and $22.2 \%$ irregular. While $41.6 \%$ were facet and $58.3 \%$ tubercle in texture. Conclusion: This study concluded that the morphological study of Gerdy's tubercle is mandatory to approach the lateral compartment of the knee joint for any surgical intervention. The calculation of safe area is so important to avoid injury to common peroneal nerve.
\end{abstract}

Key words: $\quad$ Common Peroneal Nerve, Gerdy's Tubercle, Gerdy's Safe Zone, Illiotibial Tract, Upper Lateral Compartment of Knee Joint.

Article Citation: Hussain A, Mughal IA, Hanif M. Anatomical study of Gerdy's tubercle, its shape, texture and clinical application. Professional Med J 2020; 27(5):957962. DOI: 10.29309/TPMJ/2020.27.05.3931

\section{INTRODUCTION}

Tibia is medial weight bearing bone of leg and longest next to femur. ${ }^{1}$ It consists of medial and lateral condyles, lateral condyle is larger and massive and hanging over posteriorly. The fibular facet(FF) for superior tibiofibular joint is located posteriorinferior aspect of lateral condyle. ${ }^{1}$ The facet is more triangular in shape. ${ }^{2}$ The anterolateral aspects of the condyle is separated by the shaft by a sharp margin for the attachment of illiotibial tract. This margin is having anteriorly a triangular like facet called Gerdy's Tubercle (GT) and palpable through skin. This tubercle was named after French Surgeon Pierre Nicolas Gerdys (1797-1856). This is also important because of attachment of illiotibial band of lateral thigh and usually gets fractured along with tibial tuberosity ${ }^{3,4}$ and is also a source of bone graft. ${ }^{5}$ The common peroneal nerve winds round neck of fibular and have relation nearby GT. Grays anatomy describe GT as facet on which iliotibial tract is attached and where it is superficial to and blends with the apponeurosis of vastus lateralis. ${ }^{6}$

The common peroneal nerve as it lies nearby ${ }^{7}$ is commonly injured during upper end fracture 
of tibia and fibula and surgically threatened by internal fixation and bone grafting. The present study will depict the gross feature of GT and along with marking the safe area on the upper lateral compartment of the tibia to avoid injury to common peroneal nerve.

\section{MATERIAL \& METHODS}

This Anatomical study was conducted in anatomy department of Faisalabad Medical University (FMU) Faisalabad from Nov 2018 to April 2019. Total 72 dried Pakistani tibia irrespective of sex (38 right and 34 left) were taken from the bone bank of Anatomy Department FMU.

Inclusion Criteria

a. Adult tibia

b. Upper ends preserved

Exclusion Criteria

a. Ossifying bones

b. Irrespective of sex

The upper end of tibia was studied with respect to the shape and texture of Gerdy's tubercle. The shape is divided in to Group A having triangular, Group B oval, Group with C irregular and group $D$ included unidentified in both right and left bones and their \% age was calculated. Similarly the texture Of GT was divided in to facet type (smooth), Group A, Group B tubercle (rough) in both right and left tibia and then \% age was calculated.

The safe area was calculated with the help with measuring tape and divider. Firstly Gerdy's tubercle (GT) and fibular facet (FF), (Figure-3) for superior tibiofibular joint were located. These areas are marked by marker and center point is marked as A on center of gerdys' tubercle (GT) and $B$ on the center of fibular facet (FF). The Line from point $A$ to point $B$ (A-B) (Figure-7) was the radius of an arc and will touch a vertical line dropped from Point $A$ down to shaft parallel to the Tibial Tuberosity at Point C. (Figure-7) The mean distance was calculated between point $A$ and $B(A-B)$ and make and arc this will mark the safe area for surgical procedures as shown in the Figure-7.

\section{RESULT}

Total 72 dried human tibia were examined out of which 38 were of right side and rest 34 were of left side all showed Gerdry's tubercle. Regarding shape of GT Right tibia showed group A 12(31.5\%) triangular (Figure-1, Graph-1), Group B oval shape GT was 20 (52.6\%), (Figure-2, Graph-1) number of irregular Group C was 6 (15.9\%), (Figure-3, Graph-1) and none unidentified (0\%) (Group D). Regarding texture GT Right Tibia showed Group A facet type 16(42\%) (Figure-4, Graph-2), Group B were 57\% of tubercle type (22 (Figure-5, Graph-2) and non unidentified (Group D) Zero \%.

Total 34 left tibia shape of GT was examined and found triangular group $A$ in 18 tibia (52\%) and group B oval shaped 6(17.6\%) in. Whereas in group C irregular10 (29.4\%) (Figure-6, Graph-2). The texture of left tibia $41.1 \%(\mathrm{~N}=14)$ were of facet Type Group A and 58.82\% ( $=20)$ were of tubercle type group B.

Total Number of Tibia ( $\mathrm{N}=72$ ) showed $41.6 \%$ triangular, $36.1 \%$ oval and $22.2 \%$ irregular GT. While $41.6 \%$ were facet and $58.3 \%$ tubercle in texture all values shown in Table-l.

Safe area Calculation (Table-I, Figure-7)

Mean Radius of safe area arc in right tibia $\mathrm{N}=38$ was $3.70 \pm 0.11 \mathrm{~cm}$

Mean Radius of safe area arc in left tibia $\mathrm{N}=34$ was $3.40 \pm 0.10 \mathrm{~cm}$

Mean radius of safe area arc in total $\mathrm{N}=72$ was $3.55 \pm 0.07 \mathrm{~cm}$

\section{DISCUSSION}

The present study is the description of the variation in Girdy's tubercle and its relation with the common fibular nerve, as being important land mark in the upper lateral compartment of the knee joint. The anatomical variations are discussed in groups as previously described by Sunita Kalra etal $2019 .{ }^{8}$ Girdy's tubercle is present $100 \%$ of bone contrary to be noted absent $5.8 \%$ by Sunita Kalra et al $2019^{8}$ depicts more muscular activity compared to Indian population. 


\begin{tabular}{|c|c|c|c|c|c|c|c|}
\hline $\begin{array}{l}\text { Side and } \\
\text { No. of } \\
\text { Bones }\end{array}$ & \multicolumn{3}{|c|}{ Shape } & \multicolumn{2}{|c|}{ Texture } & $\begin{array}{c}\text { Unidentified } \\
\% \\
\text { Group D }\end{array}$ & $\begin{array}{c}\text { Mean Radius of } \\
\text { Arc in } \mathrm{Cm} \\
(\mathrm{A}-\mathrm{B})\end{array}$ \\
\hline $\begin{array}{l}\text { Right } \\
N=38\end{array}$ & $\begin{array}{c}12 \\
(31.5 \%)\end{array}$ & $\begin{array}{c}20 \\
(52.6 \%)\end{array}$ & $\begin{array}{c}6 \\
(15.71 \%)\end{array}$ & $\begin{array}{c}16 \\
(42.1 \%)\end{array}$ & $\begin{array}{c}22 \\
(57.8 \%)\end{array}$ & Zero\% & $3.70 \pm 0.11$ \\
\hline $\begin{array}{l}\text { Left } \\
N=34\end{array}$ & $\begin{array}{c}18 \\
(52.9 \%)\end{array}$ & $\begin{array}{c}6 \\
(17.6 \%)\end{array}$ & $\begin{array}{c}10 \\
(29.4 \%)\end{array}$ & $\begin{array}{c}14 \\
(41.1 \%)\end{array}$ & $\begin{array}{c}20 \\
(58.82 \%)\end{array}$ & Zero\% & $3.40 \pm 0.10$ \\
\hline $\begin{array}{l}\text { Total } \\
\mathrm{N}=72\end{array}$ & $\begin{array}{c}30 \\
(41.61 \%)\end{array}$ & $\begin{array}{c}26 \\
(36.1 \%)\end{array}$ & $\begin{array}{c}16 \\
(22.2 \%)\end{array}$ & $\begin{array}{c}30 \\
(41.6 \%)\end{array}$ & $\begin{array}{c}42 \\
(58.31 \%)\end{array}$ & Zero\% & $3.55 \pm 0.07$ \\
\hline
\end{tabular}

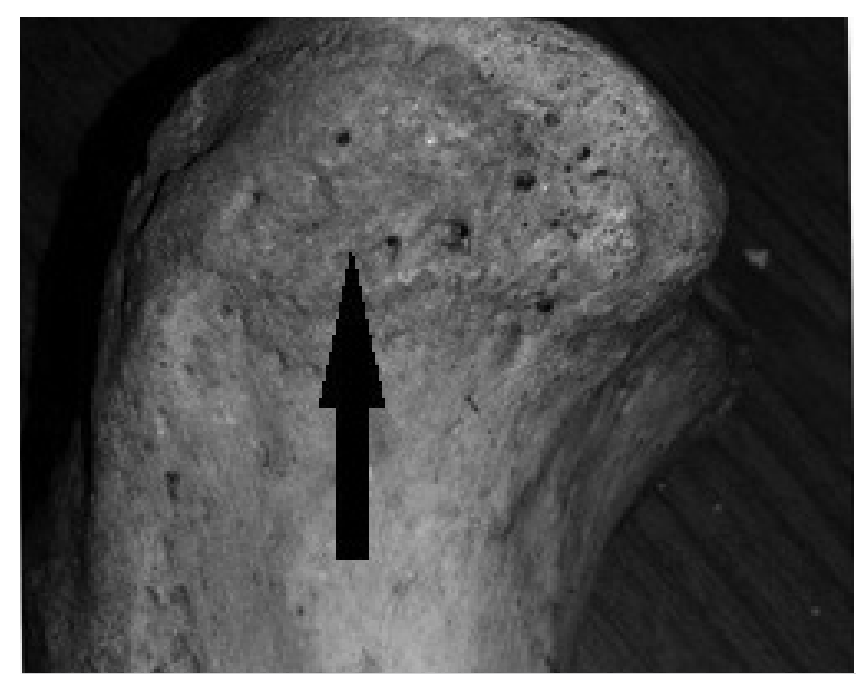

Figure-1. Right tibia triangular (GT)

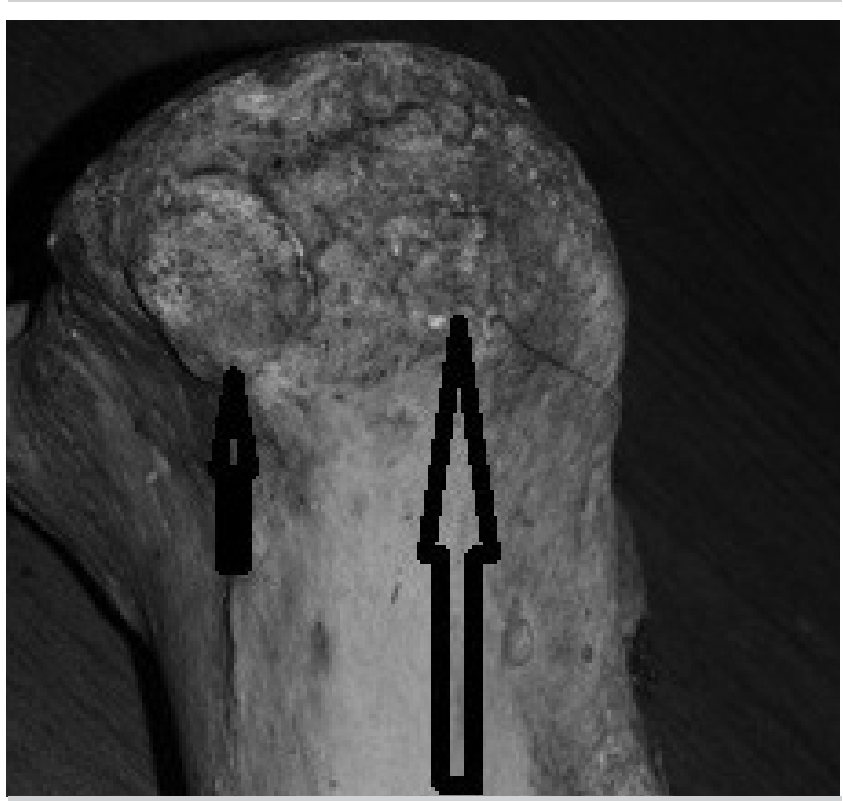

Figure-3 Long arrow (GT) Irregular Short arrow fibular facet (FF)

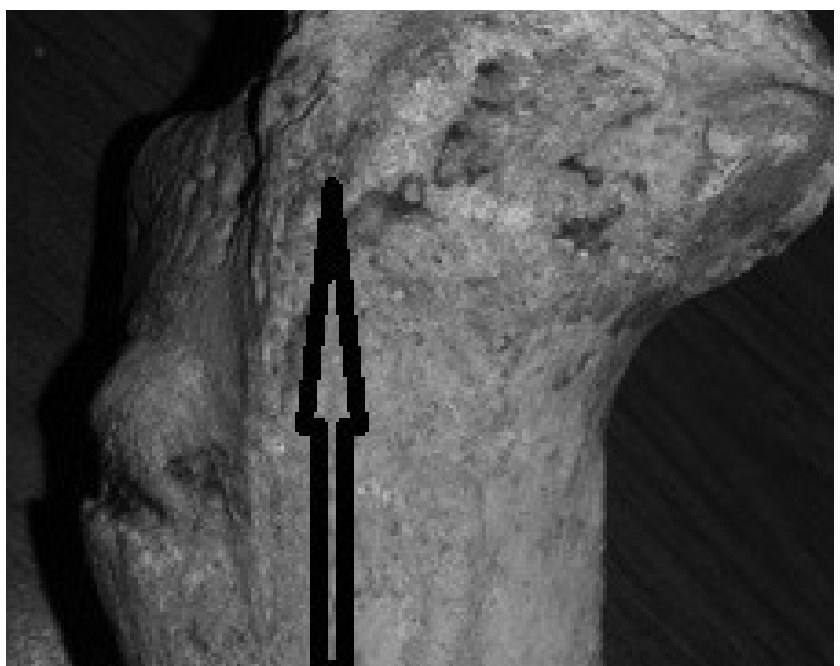

Figure-2. Right tibia oval (GT)

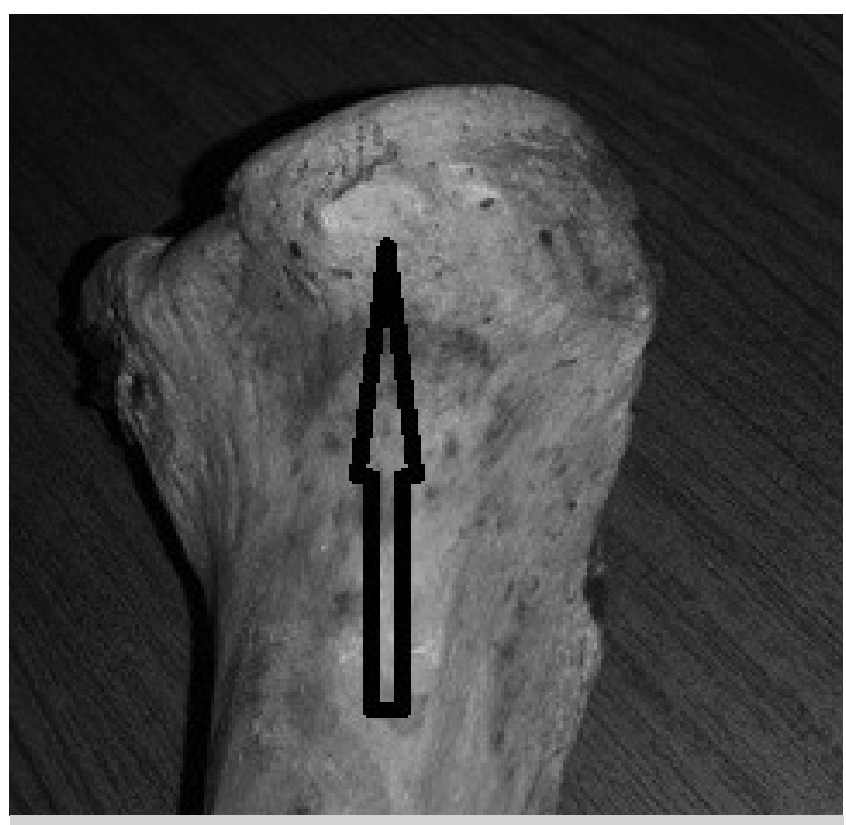

Figure-4. (GT) facet 


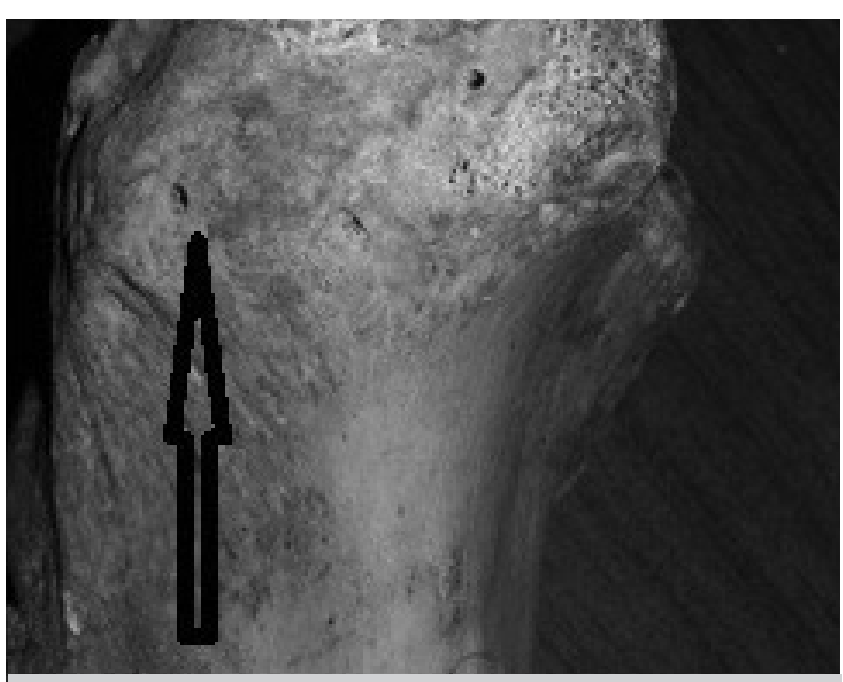

Figure-5. (GT) Irregular rough Tubercle

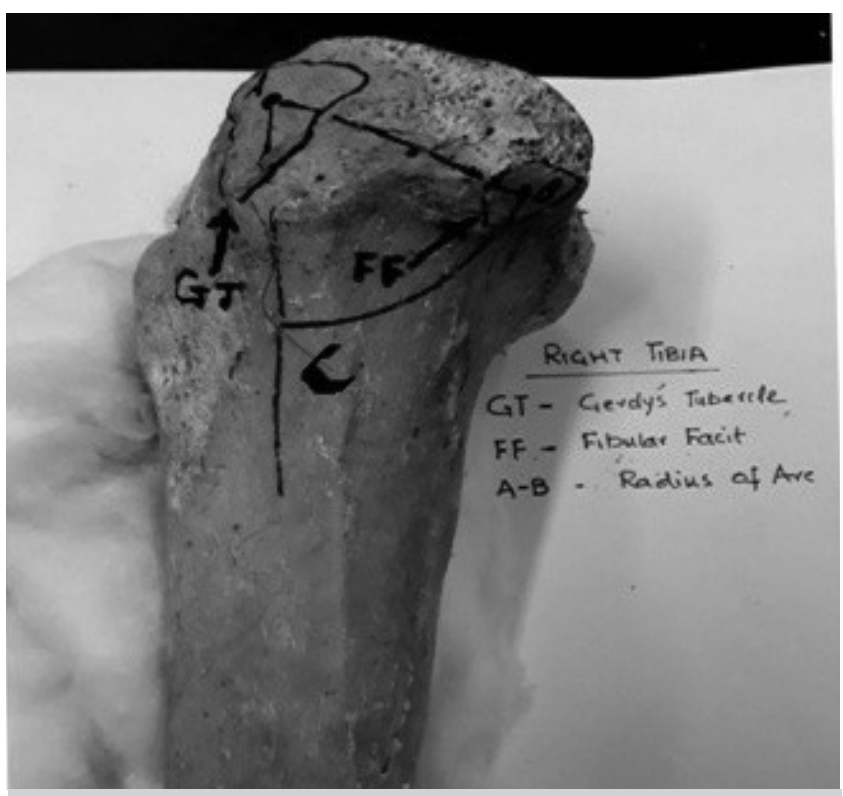

Figure-7. Safe area marking right Tibia

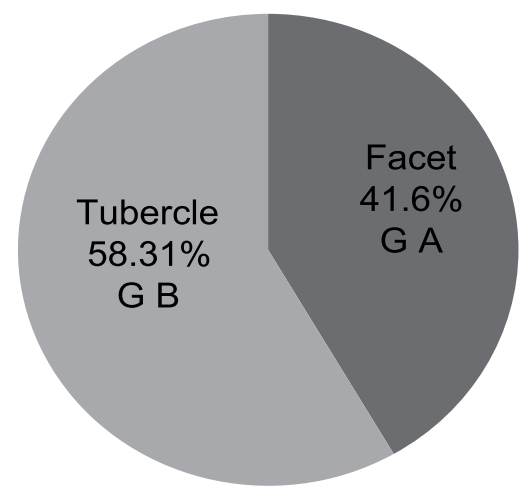

Graph-2. \% age Comparison of texure of Girdy's tubercle $\mathrm{N}=72$

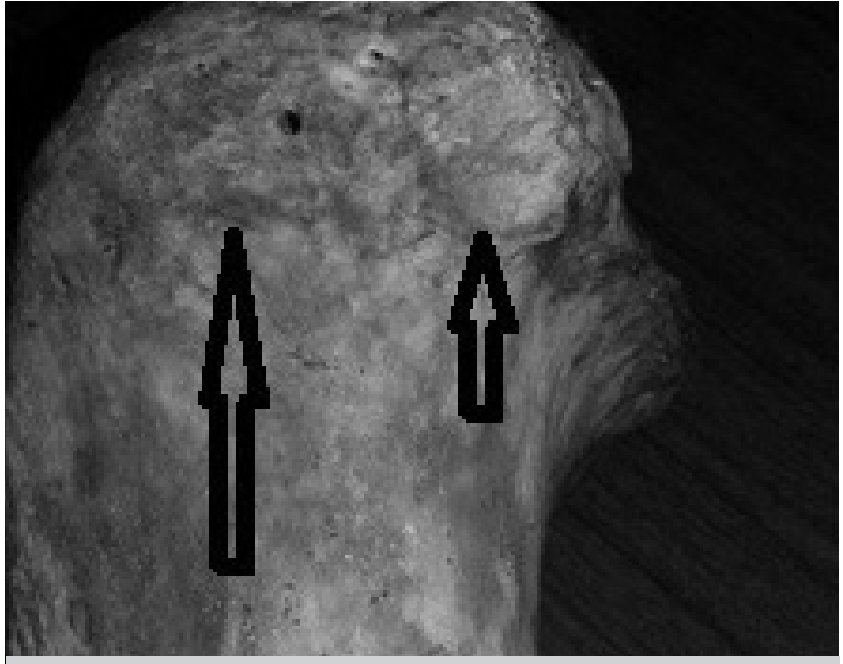

Figure-6. Rough irregular GT tubercle (Left tibia)

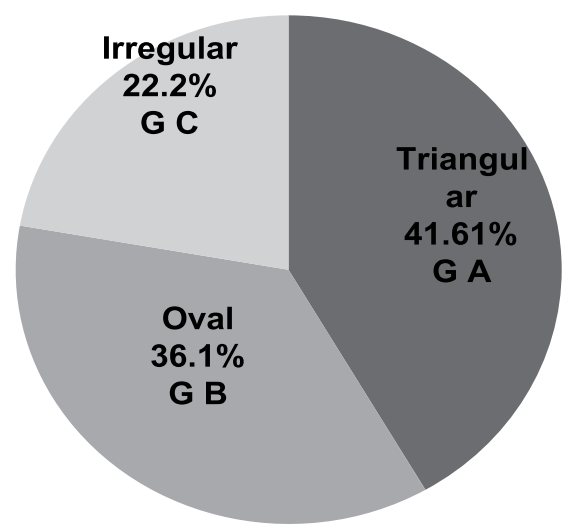

Graph-1. \% age comparison of shape of Gerdy's tubercle $\mathrm{N}=72$

Grays Anatomy describe GT as soft facet on which iliotibial tract is attached (Standring, Ellis, Healy et al 2005) ${ }^{9}$ contrary to my observation as being more tubercle in texture Table1 and graph 2. Natter, $2011^{10}$ Atlas describes GT as oval and triangular but Williams, Bannister et al $1995^{11}$ has described it to be flat and well defined. In this study triangular shape is more compared to oval (Table-I) is strengthened by other researcher as well (Agur.Dalley,2009 and Gilory et al 2012). ${ }^{12}$ The different shape and texture of the Gerdy's tubercle could be resulted due to the oblique attachment of illiotibial tract on which gluteus 
maximus and tensor fasciae latae got inserted. The importance of Girdy's tubercle lies in the fact that lateral illiotibial band insert on it as said by Starkey and chad 2009, insertion of needles for aspiration of medullary fluid in neonates as described by Yoo, Jee ho et al 2006. ${ }^{13}$ Rubel, IF et al in $2004^{14}$ also described its vital role in bone grafting.

In this article safe area was calculated in the fact that common peroneal nerve lies in its near neighbor and is commonly injured in surgical procedure as described by Khan $R$ and Birch R 2001. ${ }^{15}$ I took two bony points as reference Gerdy's tubercle and fibular articular facet while CaoThi et al $2018^{16}$ demonstrated four bony landmarks Gerdy's tubercle, Fibular head, long head of biceps femoris and lateral condyle of tibia on cadaver. In this study I calculated mean radius of arc with the center of gerdy's tubercle was $3.55 \pm 0.07 \mathrm{~cm}$ contrary to Cao Thi et al $2018^{16}$ who noted $45 \mathrm{~mm}$. The opinion in this difference was he took the distance from the stem and anterior branch of common peroneal nerve while in this article I measured from the articular facet of the head of fibula, moreover he was studying the cadaver compared to my dried bony land marks. The importance of safe area calculation was due to the fact that surgical intervention may damage of common personal nerve. Brutus and loftus $2006^{5}$ suggested bone graft might be harvested from Gerdy's tubercle avoiding injury to the nerve and same was described by Benninger et al $2012^{17}$ who proposed oblique incision from tibial tuberosity to enter through cortex to take cancellous bone sampling safely. Pedro jose $2010^{18}$ also proposed Gerdys safe area on proximal tibia for surgical procedure

\section{CONCLUSION}

This study concluded that the morphological study of Gerdy's tubercle is mandatory to approach the lateral compartment of the knee joint for any surgical intervention. The calculation of safe area is so important to avoid injury to common peroneal nerve.

Copyright@ 02 Oct, 2019.

\section{REFERENCES}

1. Grays anatomy susan stranding 43ed. P 1401-1405.

2. Anatomy of proximal tibiofibular joint $J \quad D$ Esperegueira-Mendes and M Vieira da Silva Knee surg. Sports, Taumatic artho. 2006 14:241-249.

3. Starky Chad 2009. Examination of orthopedic and athletic injury ( $3^{\text {rd }}$ ed.) F.A Davis P218 ISBN 978-93, 5025-351-9.

4. Yoo JH, Hahn SH, Yang BK, Yi SR, Ahn YJ, Yoon DJ, Kim JH. An en bloc avulsion fracture of tibial tuberosity and Gerdy's tubercle in an adolescent basketball player: a case report. Knee Surgery, Sports Traumatology, Arthroscopy. 2007 Jun 1;15(6):781-5. Doi: 10 1007/s00167-006-02138.

5. Brutus JP, Loftus JB. Gerdy's tubercle as a source of cancellous bone graft for surgery of the upper extremity: description of technique. The Journal of hand surgery. 2006 Jan 1;31(1):147-9. Doi: 10. 1016/ jhsa.2005.

6. Grays anatomy Susan standring 40ed. London 2008 P 1340 .

7. Rubil IF, Schwarzbard I, Leonard A Cece D Anatomical location of the common peroneal nerve at the level proximal aspect of tibia Gerdys safe zone. J bone, joint, surg. Am.2004 86-A(8)162-8.

8. Kalra S, Chauhan P, Khandelwal A, Rani P. Variations of Gerdy's tubercle, proposal of a morphological classification: Anatomical study and its clinical importance. Journal of Morphological Sciences. 2014 Apr;31(02):110-3.

9. Standring $\mathrm{S}$, Ellis $\mathrm{H}$, Healy J, Johnson D, Williams A, Collins P, Wigley C. Gray's anatomy: the anatomical basis of clinical practice. American Journal of Neuroradiology. 2005 Nov;26(10):2703.

10. Netter, FH. Atlas of human anatomy $5^{\text {th }} \mathbf{e d}$. Philadelphia Saunders, 2011.p497; p501-503.

11. Williams, PI., Bannister, IH., Berry, MM et al 1995 Grays Anatomy 38th ed. New York Chirchill Livingstone, P481-83., p. 692-694.

12. Agur AM, Dalley AF. Grant's atlas of anatomy. Lippincott Williams \& Wilkins; 2009.

13. Yoo JH, Hahn SH, Yang BK, Yi SR, Ahn YJ, Yoon DJ, Kim JH. An en bloc avulsion fracture of tibial tuberosity and Gerdy's tubercle in an adolescent basketball player: a case report. Knee Surgery, Sports Traumatology, Arthroscopy. 2007 Jun 1;15(6):781-5. 
14. Rubel IF, Schwarzbard I, Leonard A, Cece D. Anatomic location of the peroneal nerve at the level of the proximal aspect of the tibia: Gerdy's safe zone. JBJS. 2004 Aug 1;86(8):1625-8.

15. Khan R, Birch R. latropathic injuries of peripheral nerves. The Journal of bone and joint surgery. British volume. $2001 \mathrm{Nov} ; 83(8): 1145-8$.

16. Thi C, Van Huy N, Nguyen NC, Thanh TH. Applied anatomy of common peroneal nerve: A cadaveric study. Int J Med. 2018 Jun;6(1):6-10.
17. Benninger B, Ross A, Delamarter T. Approaches to proximal tibial bone harvest techniques. Journal of oral \& maxillofacial research. 2012 Apr;3(2).

18. Labronici PJ, Teixeira TM, Medeiros FB, Franco JS, Hoffmann R, Passos MA, Lourenço PR, Fernandes HJ, Reis FB. Comparação clínica e anatômica do nervo fibular na zona de segurança de Gerdy. Revista Brasileira de Ortopedia. 2010;45(1):23-7.

\section{AUTHORSHIP AND CONTRIBUTION DECLARATION}

\begin{tabular}{|c|l|l|}
\hline Sr. \# & \multicolumn{1}{|c|}{ Author(s) Full Name } & \multicolumn{1}{|c|}{ Contribution to the paper } \\
\hline 1 & Anwaar Hussain & Study design \& data collection. \\
\hline 2 & Irfan Ahmed Mughal & Literature review, Data analysis. \\
\hline 3 & Muhammad Hanif & $\begin{array}{l}\text { Compilating results, Drafting of } \\
\text { article. }\end{array}$ \\
\hline
\end{tabular}

